\title{
A New Approach for Thermodynamic Study on the Binding of Human Serum Albumin with Cerium Chloride
}

\author{
G. Rezaei Behbehani, ${ }^{\star}$ A. Divsalar, ${ }^{\dagger}$ A. A. Saboury, ${ }^{\dagger}$ F. Faridbod, ${ }^{\ddagger}$ and M. R. Ganjalij \\ Chemistry Department, Imam Khomeini International Lniversity, Qazwin, Iran. " E-mail: grb t02003avahoo.com \\ ${ }^{\dagger}$ Institute of Biochemistrv and Biophrsics. Chiversitv of Tehran. Tehran. Iran \\ -Departments of Chemistry, Liniversity of Tehran, Tehran, Iran \\ Received March 27, 2009, Accepted.April 26, 2009
}

\begin{abstract}
Themnodynamics of the interaction between Cerium (III) chloride, $\mathrm{Ce}^{3+}$, with Human Serum Albumin, HSA, was investigated at $\mathrm{pH} 7.0$ and $27^{\circ} \mathrm{C}$ in phosphate buffer by isothermal titration calorimetry. Our recently solvation model was used to reproduce the enthalpies of $\mathrm{HSA}$ interaction by $\mathrm{Ce}^{3+}$. The solvation parameters recotered from our new model, attributed to the structural change of HSA and its biological activity. The interaction of HSA with $\mathrm{Ce}^{3+}$ showed a set of two binding sites with negative cooperativity. Ce $\mathrm{e}^{3-}$ interacts with multiple sites on HSA affecting its biochemical and biophy sical properties.
\end{abstract}

Key Words: Human Serum Albumin. Isothermal titration calorimetry. Cerium (III) chloride.

\section{Intoduction}

Human Serum Albumin (HSA), as the most abundant protein constituent of blood plasma. has a high affinity to an extraordinarily diverse range of materials such as drugs. metabolites. fatty acids and metal ions. ${ }^{1-3}$ HSA can bind and carry through the bloodstream many drugs, which are poorly soluble in water and it is also responsible for the maintenance of blood $\mathrm{pH}$, the drug disposition and efficacy, and the contribution of colloid osmotic blood pressure. ${ }^{4-5}$ The unique feature of albumin is its ability to bind a wide variety of compounds, mainly because of the availability of hydrophobic pockets inside the protein network and the flexibility of the albumins to adapt its shape. ${ }^{6-8}$ The crystallographic analy sis of HSA revealed that this protein is a single-chain 66 $\mathrm{kDa}$ protein. which is largely $\alpha$-helical. and consists of three structurally homologous domains that assemble to form a heart-shaped molecule. Each domain is a product of two subdomains. which are predominantly helical and extensively cross-linked by several disulfide bridges. ${ }^{8-10}$

Erbium is one of the rare chemicals that can be found in houses in equipment such as color televisions. fluorescent lamps. energy-saving lamps and glasses. All rare chemicals have comparable properties. Erbium will gradually accumulate in soils and water soils and this will eventually lead to increasing concentrations in humans, animals and soil particles. The use of erbium is still growing, due to the fact that it is suited to produce cataly'sers and to polish glass. Erbium is mostly dangerous in the working environment. due to the fact that damps and gasses can be inhaled with air. This can cause lung embolisms, especially during long-term exposure. Erbium can be a threat to the liver when it accumulates in the human body. " All erbium compounds should be regarded as highly toxic because the biological properties of the lanthanides. primarily based on their similarity to calcium. have a high affinity for $\mathrm{Ca}^{3+}$ sites on biological molecules and hence can act as either $\mathrm{Ca}^{3+}$ inluibitors or probes. Although the Lanthanide cannot gain access to intracellular organelles. they have been used as biochemical probes to study calcium transport in mitochondria and other organelles. ${ }^{\text {I }}$ The biological properties of the lanthanides, primarily based on their similarity to calcium. have been the research basis into the potential therapeutic applications of lanthanides. since the early part of the twentieth century. The lanthanides have similar ionic radii to calcium, but by virtue of possessing a higher charge. they exhibit a high affinity for the $\mathrm{Ca}^{2+}$ sites on biological molecules and a stronger binding to water molecules. ${ }^{1-14}$ One of the major phy siological effects of the lanthanide $\left(\mathrm{Ln}^{3+}\right)$ ions is to block both the voltage operated and the receptor operated calcium channels. $\mathrm{Ln}^{3+}$ can block the $\mathrm{Na}^{+} / \mathrm{Ca}^{3+}$ synaptic plasma membrane exchange and inhibit the skeletal, smooth and cardiac muscle contraction by blocking the $\mathrm{Ca}^{2-}$-ATPase in the sarcoplasmic reticulum of the muscle. The $\mathrm{Ln}^{3-}$ ions themselves are unable to cross the cell membranes, but they act by blocking the exterior face of the calcium channel. Though $\mathrm{Ln}^{3-}$ cannot gain access to the intracellular organelles. they have been used as biochemical probes to study the calcium transport in mitochondria and the other organelles. ${ }^{15-16}$ The lanthanides can substitute calcium in proteins. even though it should be noted that the $\mathrm{Ln}^{3+}$ ions can also substitute other metal ions. such as $\mathrm{Mg}^{2+} . \mathrm{Fe}^{\hat{3-}}$ and $\mathrm{Mn}^{\hat{2}}$. The calcium dependent enzymes can either be inhibited by lanthanides, or in some cases. be activated to a similar or greater extent by calcium. It has been proposed that the stimulatory or inhibitory effect of the lanthanides may be a function of the role of calcium in the native enzyme. The interest in lanthanides regarding the biochemical reactions arises from the fact that they can be used as probes to unravel the interactions between $\mathrm{Ca}^{++}$and the biologically important molecules.

This work represents the most comprehensive study on the interactions between $\mathrm{Ce}^{3-}$ cations with HSA and provides new evidence for validity of our recently introduced solvation model and more insights into the interactions of $\mathrm{Ce}^{3+}$ with HSA for further understanding of the effects of metal ions on the stability and the structural changes of macromolecules. 


\section{Materials}

HSA was obtained from Sigma and $\mathrm{Ce}^{3+}$ was purchased from Merck. Protein concentrations were determined from absorbance measurements at $277 \mathrm{~mm}$ in $1 \mathrm{~cm}$ quartz cuvettes. All other materials and reagents were of analytical grade and solutions were made in $50 \mathrm{mM}$ buffer phosphate using double-distilled water.

\section{Method}

The isothermal titration calorimetric experiments were carried out on a VP-ITC ultra sensitive titration calorimeter (MicroCal. LLC. Northampton, MA). The microcalorimeter consists of a reference cell and a sample cell of $1.8 \mathrm{~mL}$ in volume. with both cells insulated by an adiabatic shield. All solutions were thoroughly degassed before use by stirring under vacuum. The sample cell was loaded with HSA solution $(40 \mu \mathrm{M})$ and the reference cell contained buffer solution. The solution in the cell was stirred at $307 \mathrm{rpm}$ by the syringe (equipped with micro propeller) filled with $\mathrm{CeCl}_{3}$ solution $(500 \mu \mathrm{M})$ to ensure rapid mixing. Injections were started after baseline stability had been achieved. The titration of HSA with $\mathrm{CeCl}_{3}$ solution involved 30 consecutive injections of the ligand solution. the first injection was $5 \mu \mathrm{L}$ and the remaining ones were $10 \mu \mathrm{L}$. In all cases. each injection was done in $6 \mathrm{~s}$ at 3 min intervals. To correct the thermal effects due to $\mathrm{CeCl}_{3}$ dilution control experiments were done in which identical aliquots were injected into the buffer solution with the exception of HSA. In the ITC experiments, the enthalpy changes associated with processes occurring at a constant temperature are measured. ${ }^{1:-a^{i}}$ The measurements were performed at a constant temperature of $27.0 \pm 0.02{ }^{\circ} \mathrm{C}$ and the temperature was controlled using a Poly'-Science water bath

\section{Results and Discussion}

We have shown previously that the enthalpies of the HSA+ $\mathrm{Ce}^{3+}$ interactions in the aqueous solvent system can be accounted for quantitatively in terms of three factors: preferential solvation by the components of a mixed solvent. weakening or strengthening of solvent-solvent bonds by the solute and the change in the enthalpy of the solute-solvent interactions. ${ }^{21-32}$ This treatment leads to:

$J H=J H_{\text {max }} x_{B}^{\prime}-\delta_{B}^{H}\left(x_{A}^{\prime} L_{A}-x_{E}^{\prime} L_{B}\right)-\left(\delta_{E}^{\theta}-\delta_{A}^{y}\right)\left(x_{A}^{\prime} L_{A}-x_{B}^{\prime} L_{B}\right) x_{B}^{\prime}$

The parameters $\delta_{A}^{A}=(\alpha n+\beta N)$ and $\delta_{b}^{\beta}=(\alpha n+\beta N)$ are the composite parameters which reflect to the net effect of $\mathrm{Ce}^{3-}$ cations on the HSA stability in the low and high $\mathrm{Ce}^{3+}$ concentrations respectively' with $a n$ resulting from the formation of a cavity wherein " $n$ " $\mathrm{Ce}^{3-}$ cations become the nearest neighbors of the HSA and $B$ N reflecting the enthalpy change from strengthening or weakening of water $+\mathrm{Ce}^{3-}$ bonds of $N$ solvent molecules $(N \geq n)$ around the cavity. The positive values for $\delta_{d}^{H}=(\alpha n+\beta N)_{A}^{\theta}$ and $\dot{\delta}_{B}^{H}=(\alpha n+\beta N)_{s}^{H}$ indicate that $\mathrm{Ce}^{3+}$ cations stabilized the HSA structure and vice versa. The constants $\alpha$ and $\beta$ reflect the proportion of the total enthalpy of water $+\mathrm{Ce}^{3-}$ binding which is associated with the cavity formation and modification of solvent structure (water + $\mathrm{Ce}^{\text {s+ }}$ ) around the cavity. respectively: Cooperative binding requires that the macromolecule have more than one binding site. since cooperativity results from the interactions between binding sites. If the binding of ligand at one site increases the affinity for ligand at another site. the macromolecule exhibits positive cooperativity. Conversely. if the binding of ligand at one site lowers the affinity for ligand at another site. the protein exhibits negative cooperativity. If the ligand binds at each site independently, the binding is non-cooperative. $p<1$ or $p>1$ indicate positive or negative cooperativity of macromolecule for binding with ligand respectively: $p=1$ indicates that the binding is non-cooperative. $x_{B}^{\prime}$ can be expressed as follows:

$$
x_{B}=\frac{p x_{B}}{x_{. t}+p x_{B}}
$$

$x_{B}$ is the fraction of the $\mathrm{Ce}^{3-}$ needed for saturation of the binding sites, and $x_{-1}=1-x_{B}$ is the fraction of unbounded $\mathrm{Ce}^{3-}$. Now the model is a simple mass action treatment, with metal ions replacing water molecules. at the binding sites in the present case. We can express $x_{S}$ fractions. as the total $\mathrm{Ce}^{3-}$ concentrations divided by the maximum concentration of the $\mathrm{Ce}^{3+}$ upon saturation of all HSA as follows:

$$
x_{B}=\frac{\left[C e^{3 i}\right]_{T}}{\left[C e^{3+}\right]_{\mathrm{mik}}} x_{A}=1-x_{B}
$$

$\left[\mathrm{Ce}^{3+}\right]_{T}$ is the total concentration of $\mathrm{Ce}^{3-}$ and $\left[\mathrm{Ce}^{3+}\right]_{\max }$ is the maximum concentration of the $\mathrm{Ce}^{\text {s+ }}$ upon saturation of all HSA. In general. there will be " $g$ " sites for binding of $\mathrm{Ce}^{3+}$ per HSA molecule and $v$ is defined as the average moles of bound $\mathrm{Ce}^{3+}$ per mole of total HSA. $L_{A}$ and $L_{B}$ are the relative contributions of unbounded and bounded $\mathrm{Ce}^{3-}$ to the enthalpies of dilution of $\mathrm{CeCl}_{2}$ with the exclusion of HSA and can be calculated from the enthalpies of dilution of $\mathrm{CeCl}_{3}$ in buffer, $\Delta H_{\text {ditut }}$ as follows:

$$
\begin{aligned}
& L_{t}=\Delta H_{\text {diht }}+x_{B}\left(\frac{\partial \Delta H_{\text {dihat }}}{\partial x_{B}}\right), \\
& L_{B}=\Delta H_{\text {diht }}-x_{A}\left(\frac{\partial \Delta H_{\text {dthti }}}{\partial x_{t}}\right)
\end{aligned}
$$

The enthalpies of $\mathrm{HSA}+\mathrm{Ce}^{3-}$ interactions. $\Delta H$, were fitted to Eq. l over the whole $\mathrm{Ce}^{3-}$ compositions. In the procedure the only adjustable parameter $(p)$ was changed until the best agreement between the experimental and calculated data was approached (Fig. 1). $\delta_{t}^{*}$ and $\delta_{B}^{\theta}$ parameters have been also optinized to fit the data. The optimized $\delta_{A}^{A}$ and $\delta_{H}^{*}$ values are recovered from the coefficients of the second and third terms of Eq. 1. The small relative standard coefficient errors and the high $r$ values (0.99999) support the method. The binding parameters for $\mathrm{HSA}+\mathrm{Ce}^{3-}$ interactions recovered from $\mathrm{Eq} .1$ were listed in Table 1. The agreement between the calculated 


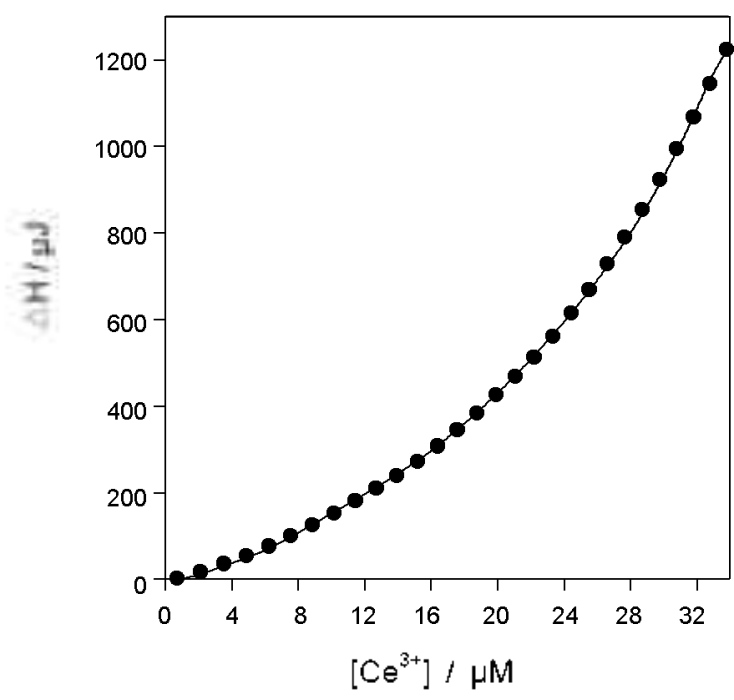

Figure 1. Comparison between the esperimental enthalpies, $\Delta \mathrm{H}$, for $\mathrm{HSA}+\mathrm{Ce}^{2-}$ interactions ( ) and calculated data (lines) via Eq. 1 .

Table 1. Enthalpies of $\mathrm{HSA}+\mathrm{Ce} \mathrm{s}^{3+}$ interactions, $\mathrm{H}$, in $\mathrm{Ce}^{\hat{s-}}$ solution with water at $300 \mathrm{~K} \mathrm{in} \mathrm{kJ} \mathrm{mol}^{-1}: H_{\text {chtrat }}$ is the enthalpies of dilution of $\mathrm{Ce}^{3+}$ with water. Precision is $\pm 0.400 \mu \mathrm{J}$ or better

\begin{tabular}{llll}
\hline$\left[\mathrm{Ce}^{3-}\right] / \mu \mathrm{M}$ & $\Delta H / \mu \mathrm{J}$ & $\Delta H_{\text {drtut }} / \mu \mathrm{J}$ & {$[\mathrm{HSA}] / \mu \mathrm{M}$} \\
\hline 0.7112376 & 2.0887042 & 0.9428408 & 44.839972 \\
2.1186441 & 16.040917 & 3.5892824 & 44.523305 \\
3.5063114 & 35.152086 & 2.8643032 & 44.21108 \\
4.8746518 & 53.890023 & 2.3254594 & 43.903203 \\
6.2240664 & 75.783316 & 0.7497666 & 43.599585 \\
7.5549451 & 99.083849 & -0.475433 & 43.300137 \\
8.8676671 & 124.04309 & -2.738694 & 43.064775 \\
10.162602 & 151.10382 & -5.353451 & 42.713415 \\
11.440108 & 180.42677 & -8.446066 & 42.425976 \\
12.700535 & 209.32538 & -10.22587 & 42.14238 \\
13.944223 & 238.57877 & -12.63735 & 41.86255 \\
15.171504 & 272.07825 & -15.85675 & 41.586412 \\
16.3827 & 306.86743 & -18.09911 & 41.313893 \\
17.578125 & 344.13927 & -21.22295 & 41.044922 \\
18.758085 & 383.93124 & -23.82245 & 40.779431 \\
19.922879 & 424.74196 & -26.74067 & 40.517352 \\
21.072797 & 467.73297 & -29.84252 & 40.258621 \\
22.208122 & 512.63445 & -33.51361 & 40.003173 \\
23.32913 & 561.334 & -36.85502 & 39.750946 \\
24.43609 & 614.44173 & -40.69335 & 39.50188 \\
25.529265 & 669.22532 & -44.33178 & 39.255915 \\
26.608911 & 727.69574 & -47.70793 & 39.012995 \\
27.675277 & 788.93065 & -51.4673 & 38.773063 \\
28.728606 & 853.81211 & -55.34299 & 38.536064 \\
29.769137 & 922.02473 & -59.26371 & 38.301944 \\
30.797101 & 993.42001 & -63.6224 & 38.070652 \\
31.812725 & 1067.5611 & -67.71909 & 37.842137 \\
32.816229 & 1145.1919 & -72.53487 & 37.616348 \\
\hline & & & \\
& & & \\
& &
\end{tabular}

and experimental results (Fig. 1) is striking. and gives considerable support to the use of Eq. 1 .

$\Phi$ is the fraction of HSA molecule undergoing complexation with $\mathrm{Ce}^{3+}$ which can be expressed as follows:

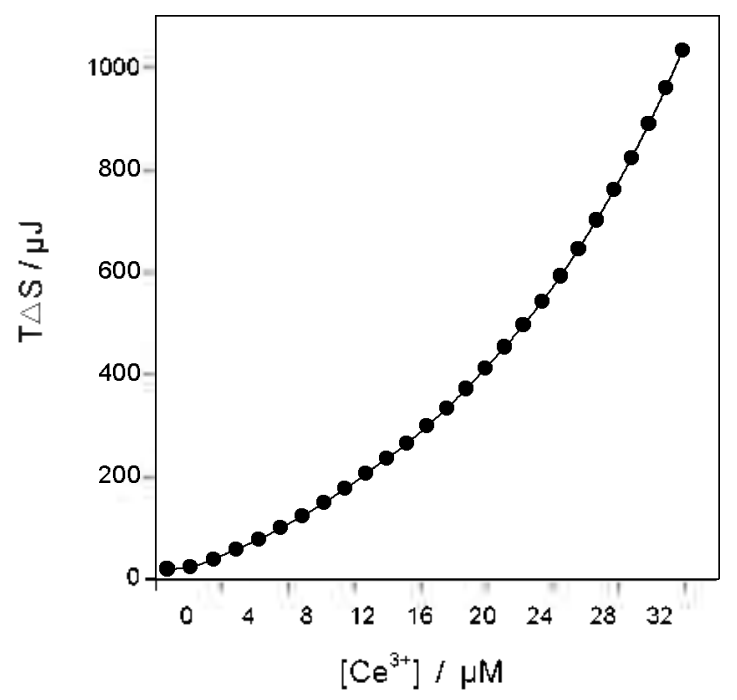

Figure 2. Comparison between the experimental entropies $(\bullet$ ) for $\mathrm{HSA}+\mathrm{Ce}^{3+}$ interactions and calculated data (lines) wia Eq. 8.

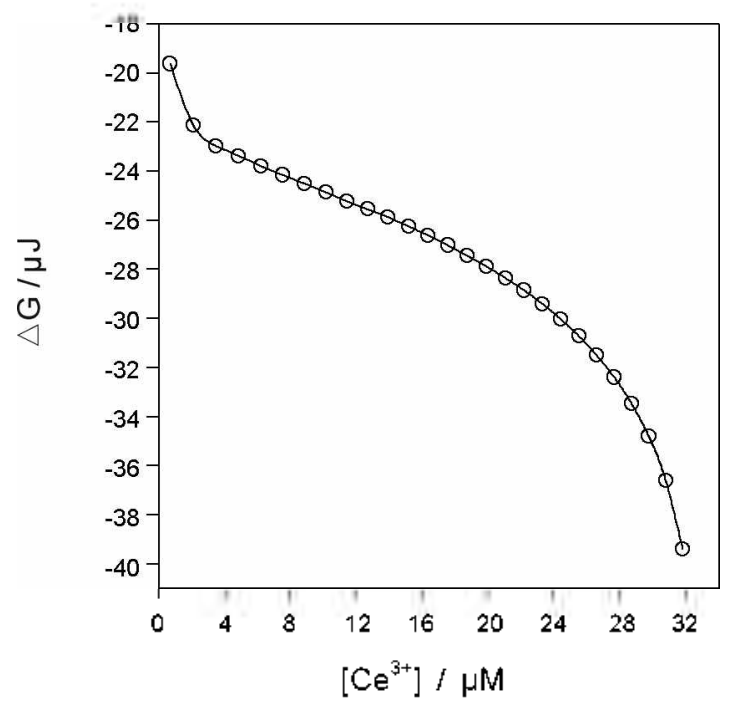

Figure 3. Comparison between the experimental free energies (o) for $\mathrm{HSA}+\mathrm{Ce}^{3+}$ interactions and calculated data (lines).

$$
\Phi=\frac{\Delta H}{\Delta H_{\max }}
$$

$\Delta H_{\text {mix }}$ represents the heat value upon saturation of all HSA. The appearance association equilibrium constant values. $K_{a}$. as a function of $\mathrm{Ce}^{3-}$ free concentration. $\left[\mathrm{Ce}^{3-}\right]_{\mathrm{F}}$, can be calculated as follow:

$$
K_{2}=\frac{\Phi}{(1-\Phi)\left[C e^{3-}\right] F}=\frac{\Phi}{(1-\Phi)\left(1-x_{B}\right)\left[C e^{3+}\right] \tau}
$$

The association equilibrium constants for successive replacement of water molecules by $\mathrm{Ce}^{3-}$ cations are as follows

$$
K_{s}=x_{t}^{z}-\sum_{i=1}^{g} K_{i} \frac{x_{B}^{i}}{x_{i}^{i-g}}
$$


Table 2. Thermodynamic parameters for HSA $+\mathrm{Ce}^{3+}$ interactions in $\mathrm{Ce}^{\text {:- }}$ solution with water via Eq. 1 .

\begin{tabular}{cc}
\hline parameters & $\mathrm{HSA}+\mathrm{Ce}^{3-}$ \\
\hline$p$ & 0.280 \\
$\delta_{. t}^{0}$ & $2.134 \pm 0.075$ \\
$\delta_{B}^{e}$ & $2.134 \pm 0.001$ \\
$K_{1} / \mu \mathrm{M}^{1}$ & $2.004 \pm 0.014$ \\
$K_{2} / \mu \mathrm{M}^{1}$ & $1.161 \pm 0.011$ \\
\hline
\end{tabular}

$\mathrm{K}_{\mathrm{i}}$ 's are the microscopic association equilibrium constants for the equilibria:

$$
\mathrm{HSH}_{\mathrm{i}}\left(\mathrm{H}_{2} \mathrm{O}\right)_{\mathrm{g}}+i\left(\mathrm{Ce}^{3-}\right) \Leftrightarrow \mathrm{HSH}_{\mathrm{i}}\left(\mathrm{H}_{2} \mathrm{O}\right)_{\mathrm{g}-i}\left(\mathrm{Ce}^{3+}\right)_{i}
$$

$K_{4}$ values obtained from Eq. 6. have been fitted to Eq. 7 using a computer program for nonlinear least-square fitting. Therefore. we can approach to " $g$ " value simply ( $g=2$ in this work). The Gibbs free energies as a function of $\mathrm{Ce}^{3-}$ concentrations can be obtained as follows:

$$
\Delta G=-R T L n K_{a}
$$

Eqs. 6 and 7 allow us to have the $K_{\alpha}$ values in every concentrations of $\mathrm{Ce}^{3+}$ with the least standard deviations and correlation coefficients are so close to one. Gibbs energies. $\Delta G$. calculated from Eq. 8 have shown graphically in Fig. 2. $\Delta S$ values were calculated using $\Delta G$ values and have shown in Fig. 3.

Previous reports revealed that some molecules such as different species of metal ions of mercury ${ }^{33}$ paclitaxel and $\mathrm{Cu}$ (II) complex of 5.10.15.20-tetrakis (4-k-benzyl-pyridyl) porphyrin bind in the two distinct sites with different affinity on HSA which is in a good agreement with our results. ${ }^{34}$

A nonpolar residue dissolved in water induces a solvation shell in which water molecules are highly ordered. When two nonpolar groups come together on the folding of a polypeptide chain, the surface area exposed to the solvent is reduced and part of the highly ordered water in the solvation shell is released to bulk solvent which results to an increase in the entropy. It is possible to introduce a correlation between change in $\delta_{4}^{f}$ and increase in the stability of $\mathrm{HSA}+\mathrm{Ce}^{3+}$ complex. The positive values of $\partial_{A}^{\theta}$ and $\partial_{a}^{\theta}$ show that HSA is substantially stabilized against unfolding by $\mathrm{Ce}^{3+}$ ions. Therefore. by the definition given above. HSA can serve as a reasonable model of specific binding interactions for $\mathrm{Ce}^{3-}$ ions. The positive $\delta_{.}^{\partial}$ and $\delta_{B}^{\theta}$ values (Table 2) for $\mathrm{HSA}+\mathrm{Ce}^{3-}$ interaction, indicate that the HSA stnicture is stabilized as a result of its interaction with $\mathrm{Ce}^{3+}$ ions. resulting in an increase in its biological activity. $\delta_{A}^{\theta}$ and $\delta_{P}^{\theta}$ values are equal, indicating that the most of HSA is in its native form.

$p$ value is less than one $(p=0.28)$, which indicates that there is negative cooperativity in two binding sites of HSA. $K_{2}<K_{1}$ (Table 2) would indicate that binding of the second site is inhibited (anticooperativity or negative cooperativity). This conclusion is in a good agreement with cooperativity prediction by $\mathrm{Eq}$. 1 as $p$ value recovered from this equation is 0.28 .
HSA is a large globular protein with several physiological roles ranging from transport of hydrophobic metabolites. such as fatty acids and bilinubin. to the maintenance of the blood osmotic pressure and transport of metal ions like $\mathrm{Cu}^{2+} . \mathrm{Ni}^{2-}$ and $\mathrm{Zn}^{2-}$. Human serum albumin contains the $\mathrm{N}$-terminal sequence N-Asp-Ala-His-Lys, and is able to strongly bind the metal ions (especially, transition metals such as $\mathrm{Co}$. $\mathrm{Cu}$ and $\mathrm{Ni}$ ) with a high affinity for nitrogen through the donor set $\left(\mathrm{NH}_{2} . \mathrm{N}^{-}, \mathrm{N}^{-} \cdot \mathrm{N}_{\text {wnsil }}\right)$. where $\mathrm{NH}_{2}$ represent the terminal amino. $N$ the deprotonated amide groups of residues 2 and 3 and $N_{\text {urud }}$ the inidazole nitrogen belonging to His-3. ${ }^{35.26}$ The characterization of the metal-transport site of HSA was carried out by Laussac and Sarkar ${ }^{26}$ who established the participation of $\alpha-\mathrm{NH}_{2}$. two intervening peptide nitrogen atoms. the imidazole nitrogen atom of the histidine residue in the third position, and the side chain carboxyl group of Asp-1 in a penta-coordinate structure. ${ }^{36}$.37 Previous studies have shown that that albumin binds one Vanadium, $\mathrm{VO}^{-+}$, at the $\mathrm{N}$-terminal part (the "strong" site) and several other ions via non-specific interactions with carboxylate side chains of surface anino acids ("weak" sites): the exact number of such non-specific $\mathrm{VO}^{2+}$ binding sites is at least five and possibly as many as twenty. ${ }^{35}$ Therefore, it might be concluded that one of the binding site of $\mathrm{Ce}^{3+}$ on HSA is located at N-terminal part (the "strong" site. from $\mathrm{K}$ value (Table 2)) and the other weaker binding site might be located at carboxylate side chains of surface amino acids. The thermody namic parameters obtained from the binding studies of the $\mathrm{Ce}^{3-}$ complex to the HSA carrier proteins may be useful in the evaluation of the structural changes induced by the ligand on the carrier protein structure.

Acknowledgments. Financial support from the Universities of Imam Khomeini (Qazvin) and Tehran are gratefully acknowledged.

\section{Refelences}

1. Wanga, T:: Xianga, B.: Wang, Y: Chen, C.: Dong, Y.: Fang, H.; Wang. M. Colloids Surf. B: Biointerfaces 2008, 65, 113.

2. Yue, Y.; Chen, X.; Qin, J.; Yao, X. Dyes and Pigments 2008, 79 , 176.

3. Wahed, A. A.: Sridhar Rao, K.; Gupta, P. D. Anal. 2000, $287,3$.

4. Fichtl, B.; Nieciecki, A. V.: Walter, K. Idv Dnig Res. 1991, 20 , 117.

5. Rieutord, A.; Bourget, P.; Troche, G.; Zazzo, J. F. Int. J. Pham. $1995,119,57$

6. Xiao, Q.: Huang, S.; Lill, Y. Biochim. Biophus Acta (BB.t) Proteins \& Proteomics 2008, 1784, 1020.

7. Colmenarejo, G. 11ed. Res. Rev. 2003, 23, 275

8. Zhou, Q. T.; Xiang, T. F.; Tang, Y. L.; Liao, J. P; Yu, C. Y.; Zhang, H.: L., L.: Yang, Y. Y, Xu, G. Z. Colloids Suif B. Biointeifaces 2008, 61,75

9. Nagaoka, T.; Fukuda, T.; Hashizume, T.; Nishivama, T.; Tada, H.; Yamada, H.; Salomon, D. S.; Yamada, S.; Kojima, L.; Seno, M.J. Aol Biol. 2008, 380,83 .

10. Zhang, G.: Que, Q.: Pan, T.: Guo, T. J. Whol Struct. 2008, 881, 132.

11. Haghighi, B.; Papari, M. M: Shahidi, D. J. Chin. Chem. Soc. $2008,55,245$.

12. Fricker, S. P. Chent Soc. Rev 2006, 35, 524

13. Wang, K.; Cheng, Y.; Yang, X.; Li, R. Met. Ions Biol Syst. 2003, 40.707

14. Evans, C. H. Thends Biochent. Sci. 1983, $8,445$. 
15. Tann, J.: Marcus, R. A. J. Chin Chem. Soc. 2006, 53, 1.

16. Yeung, E. W; Head, S. I.; Allen, D. G. J. Phvsiol-London 2003, 552,449

17. Saboury, A. A. J. Therm. Anal. Cal. 2003, 72,93.

18. Saboun, A. A. J. Therm. Anal. Cal 2004, 77, 997.

19. Saboury, A. A. J. Iran Chem. Soc. 2006, 3, 1

20. Saboury, A. A.: Moosavi-Movahedi, A. A. Int. J. Phamac. 2002, 237,47 .

21. Rezaei Behbehani, G.; Saboury A. A. J. Them Anal Cal. 2007, 89,852

22. Rezaei Behbehani, G.: Saboury A. A.: Bagheri A. F. J. Them. Anal. Cal. 2008, 93,479 .

23. Rezaei Behbehani, G.; Tazikeh E.: Saboury A. A. Bull. Korean Chem. Soc. 2006, $27,208$.

24. Rezaei Behbehani, G.: Ghamamy S.: Waghonte, W. E. Thermochim. Acta 2006, $48,37$.

25. Rezaei Behbehani, G.; Saboury A. A. Thermochm .Acta 2007, 452,76 .
26. Rezaei Behbehani, G.; Saboury A. A. J. Them . Anal. Cal. 2007. 89.859.

27. Rezaei Behbehani, G.: Sáboury A. A. J. Colloids Suf. B: Biointerfaces 2007,61,224

28. Rezaei Behbehani, G. Bull. Korean Chent. Soc. 2005, 26, 238.

29. Rezaei Behbehani, G. Acta Chimica Slov 2005, 52, 288

30. Rezaei Behbehani. G. J. Solution. Chem. 2007. 36.939.

31. Rezaei Behbahani, G.; Saboury, A. A.; Fallah Baghery, A. $J$. Solution Chem. 2007, 36, 1311

32. Rezaei Behbahani, G.: Saboury, A. A.: Taleshi, E. J. Solution Chem. 2008, 37,619.

33. Paal, K: Muller, J.; Hegedus, L. Eur: J. biocitent. 2001, $268,2187$.

34. Bordbar, A.; Eslami, A.; Tangestaninejad, S. Polish J. Chem. $2003,77,283$.

35. Sanna, D.: Garribba, E.: Micera, G. J. Inoig. Biochem. 2009. 103,648 .

36. Lausaac, T. P.; Sarkar, B. Biochemistry. 1984, $23,2832$.

37. Silva, S.: Silva, R. M; Silva, K. M. N. J. Hol Strict. 2004, $711,73$. 